\title{
Inventarisatie van het onderwijs in de spoedeisende geneeskunde in de opleiding tot basisarts in Nederland
}

\author{
J.M.Th. Draaisma, G. Roest, R.G. van Kesteren, A. Vulto, mede namens de Commissie Spoedeisende \\ Geneeskunde VVAA
}

\section{Samenvatting}

Inleiding: Om inzicht te krijgen in het huidige onderwijs in de spoedeisende hulp aan de medische faculteiten, is het structurele onderwijs in de spoedeisende geneeskunde aan geneeskundestudenten in Nederland geïnventariseerd.

Methoden: De inhoud, het type, de plaats in de opleiding en de doeltreffendheid van het onderwijs betreffende spoedeisende hulp werd zowel door documentanalyse als interviews geïnventariseerd.

Resultaten: In het Raamplan 2001 artsopleiding wordt als eindterm gesteld dat "(...) de arts in staat is basale eerste hulp te verlenen zoals beschreven in Advanced Trauma Life Support (ATLS)." Wat betreft de spoedeisende geneeskunde lopen de door de medische faculteiten geformuleerde doelstellingen uiteen van het opleiden tot het niveau van 'goed getrainde leek' tot het niveau van huisarts. Er lijkt soms te weinig tijd in het curriculum te zijn en een tekort aan vakinhoudelijk en didactisch bekwame docenten om dit onderwijs goed te kunnen verzorgen. Er bleek geen toename van het zelfvertrouwen van de ondervraagde jaarvertegenwoordigers gedurende hun opleiding en het vertrouwen in hun capaciteiten om spoedeisende hulp te verlenen aan kinderen was en bleef laag.

Discussie en conclusie: Er lijkt een verschil te bestaan tussen de vereiste en geconstateerde situatie. Wij pleiten daarom voor aanpassingen in het medisch onderwijs die een niveau bewerkstelligen waarop de kennis en vaardigheden betreffende elementaire eerstehulpverlening en basale reanimatie voldoende zijn om deze ook daadwerkelijk in de praktijk te kunnen toepassen. (Draaisma JMTh, Roest G, Kesteren RG van, Vulto A, mede namens de Commissie Spoedeisende Geneeskunde VVAA. Inventarisatie van het onderwijs in de spoedeisende geneeskunde in de opleiding tot basisarts in Nederland. Tijdschrift voor Medisch Onderwijs 2006;25(3):117-124.)

\section{Inleiding}

Het verlenen van elementaire eerste hulp en basale reanimatie kan een aanzienlijke gezondheidswinst opleveren en de kans op blijvende invaliditeit verminderen. Van artsen wordt dan ook verwacht dat zij adequate eerste hulp en basale reanimatie kunnen toepassen. De vraag is in welke mate het onderwijs aan basisartsen daartoe is ingericht.

Om inzicht te krijgen in het huidige onderwijs betreffende spoedeisende hulp aan de medische faculteiten, is het structurele onderwijs in de spoedeisende geneeskun- de aan geneeskundestudenten in Nederland geïnventariseerd. In het Raamplan 1994 artsopleiding wordt gesteld dat “(...) de arts in staat is te handelen op minstens eerstehulpniveau, zoals thans omschreven in het Oranje Kruis-boekje."1 In het Raamplan 2001 artsopleiding: bijgestelde eindtermen van de artsopleiding wordt gesteld dat "(...) de arts in staat is basale eerste hulp te verlenen zoals beschreven in Advanced Trauma Life Support." 2 Bovendien wordt in het Raamplan 2001 gesteld: “(...) de arts geeft blijk van besef dat voor het functioneren als arts vereist is, 
dat hij kan omgaan met acute situaties." De diverse spoedeisende problemen zijn impliciet ondergebracht in de problemenlijst van het raamplan.

In dit onderzoek wordt onder spoedeisende geneeskunde het geheel aan kennis en handelingen verstaan dat gericht is op elementaire eerstehulpverlening en basale reanimatie, zoals omschreven in het Oranje Kruis-boekje. ${ }^{3}$

\section{Methoden}

\section{Deelnemende instituten}

In 2004 werden alle acht medische faculteiten in Nederland benaderd om deel te nemen aan dit onderzoek. Zij worden in het vervolg in willekeurige volgorde A $t / m$ $\mathrm{H}$ genoemd.

\section{Instrumenten}

\section{Documenten}

Geïnventariseerd werd welke onderdelen van de spoedeisende geneeskunde werden aangeboden en op welke wijze deze werden onderwezen. Hierbij is gebruik gemaakt van studiegidsen en syllabi van cursussen waarin spoedeisende geneeskunde werd onderwezen.

\section{Interviews}

Het onderwijs in de spoedeisende geneeskunde in de opleiding tot basisarts werd geïnventariseerd door afname van semigestructureerde interviews met curriculumcoördinatoren en betrokken docenten. Hierbij kwamen de volgende drie onderdelen aan bod.

\section{Algemene kenmerken van het onderwijs in de spoedeisende geneeskunde}

Over dit onderdeel werd een medewerker van de faculteit bevraagd, die inzicht had in het gehele curriculum. De vragen waren gericht op het verkrijgen van informatie over de gehanteerde eindtermen, de richtlijnen voor het onderwijs, de certificering van docenten en de momenten waarop het onderwijs plaats vond.

\section{Inhoud van het onderwijs}

Dit onderdeel werd geïnventariseerd bij de verantwoordelijke docenten. Er werd informatie ingewonnen over het aangeboden onderwijs in spoedeisende geneeskunde op het gebied van acute ziektebeelden, ongevallen en vergiftigingen. Tevens werd gevraagd of het onderwijs theoretisch en/ of praktisch aangeboden werd. Afsluitend werd gevraagd of gedacht werd dat de studenten voldoende onderwezen werden in de spoedeisende geneeskunde.

\section{Indicatie doeltreffendheid van het onderwijs} Aan de jaarvertegenwoordigers van jaar 16 (van elk jaar één) van elke medische faculteit werd gevraagd aan te geven hoe zij hun vaardigheden inschatten op het gebied van de beoordeling van de ademweg, de ademhaling, de circulatie en het bewustzijn van een volwassen slachtoffer en van een slachtoffer tussen 0-8 jaar. Aanvullend werd hen gevraagd om een inschatting te geven van hun zelfvertrouwen in het adequaat kunnen onderhouden van een vrije luchtweg en het ondersteunen van de ademhaling en circulatie door middel van beademing en thoraxcompressie bij een volwassen slachtoffer, een slachtoffer tussen 0-1 jaar en een slachtoffer tussen 1-8 jaar. Hierbij werd gebruik gemaakt van de $100 \mathrm{~mm}$ Visual Analogue Scale, waarbij 0 mm geen zelfvertrouwen en $100 \mathrm{~mm}$ een absoluut zelfvertrouwen aangeeft. ${ }^{4}$

\section{Resultaten}

\section{Documenten}

Over het algemeen waren de eerste twee jaar ingericht met onderwijsblokken waarin o.a. de anatomie, de ademhaling, de circulatie 
Tabel 1 Algemene kenmerken van de spoedeisende geneeskunde in kernblokken in de diverse curricula.

\begin{tabular}{|c|c|c|c|c|c|}
\hline $\begin{array}{l}\text { Medische } \\
\text { faculteit }\end{array}$ & Blokken & Jaar & Vorm & Contacturen & Toetsing \\
\hline \multirow[t]{4}{*}{ A } & Milieu Interieur & 2 & Th & 11 & Th \\
\hline & $\mathrm{EHBO}$ & 3 & Th/pr & 10 & Nee \\
\hline & Berwegingsapparaat & 4 & Th & 12 & Th \\
\hline & De patiënt & 4 & Th/pr & 36 & Th \\
\hline \multirow[t]{5}{*}{ B } & Lijnonderwijs & 1 & Th/pr & 4 & Entreetoets \\
\hline & Oncologie \& trauma & 3 & Th & 26 & Th \\
\hline & Acuut verlies van functie & 3 & Th & 30 & Th \\
\hline & Lijnonderwijs & 4 & $\operatorname{Pr}$ & 2 & Nee \\
\hline & Lijnonderwijs & 5 & $\operatorname{Pr}$ & 2 & Nee \\
\hline \multirow[t]{5}{*}{ C } & Praktisch klinisch onderwijs & 3 & Th/pr & 3 & Stationstoets \\
\hline & Bewegingsapparaat & 3 & Th & 4 & Th \\
\hline & Acute geneeskunde & 4 & Th/pr & 46 & Th \\
\hline & Praktisch klinisch onderwijs & 4 & Th/pr & 3 & Stationstoets \\
\hline & Centraal coschap & $5 / 6$ & $\operatorname{Pr}$ & 8 & Stationstoets \\
\hline \multirow[t]{3}{*}{$\mathrm{D}$} & Lijnonderwijs & 1 & $\operatorname{Pr}$ & $?$ & Nee \\
\hline & Trauma & 2 & Th & 29 & Th \\
\hline & Algemeen coschap & 4 & $\mathrm{Th} / \mathrm{pr}$ & 9 & Nee \\
\hline \multirow[t]{6}{*}{$E$} & Acute nood & 1 & Th & 36 & Th \\
\hline & Traumata & 1 & Th & 24 & Th \\
\hline & Ademnood & 1 & Th & 24 & Th \\
\hline & Shock & 1 & Th & 14 & Th \\
\hline & Skillslab & 1 & $\operatorname{Pr}$ & 12 & $\operatorname{Pr}$ \\
\hline & ATLS* & 4 & $?$ & $?$ & $?$ \\
\hline \multirow[t]{5}{*}{$\mathrm{F}$} & Praktisch lijnonderwijs & 1 & $\operatorname{Pr}$ & 6 & Stationstoets \\
\hline & Praktisch lijnonderwijs & 2 & $\operatorname{Pr}$ & 6 & Stationstoets \\
\hline & Acute geneeskunde & 3 & Th & 38 & Th \\
\hline & Acute chirurgie & 3 & Th & 38 & Th \\
\hline & Praktisch lijnonderwijs & 3 & $\operatorname{Pr}$ & 30 & Stationstoets \\
\hline \multirow[t]{5}{*}{ G } & Spoedeisende medische assistentie & 1 & Th/pr & 8 & $\operatorname{Pr}$ \\
\hline & Bewegingsapparaat & 2 & Th & 8 & Th \\
\hline & Spoedeisende medische assistentie & 3 & $\operatorname{Pr}$ & 3 & Nee \\
\hline & Spoedeisende medische assistentie & 5 & $\operatorname{Pr}$ & 5 & Nee \\
\hline & Grootschalig lijnonderwijs & Nvt & Th & 1 & Th \\
\hline \multirow[t]{6}{*}{$\mathrm{H}$} & $\mathrm{EHBO}$ & 1 & $\mathrm{Th} / \mathrm{pr}$ & 12 & Nee \\
\hline & Vaardigheidsonderwijs & 3 & $\operatorname{Pr}$ & 2 & Nee \\
\hline & Vaardigheidsonderwijs & 4 & $\operatorname{Pr}$ & 2 & $?$ \\
\hline & Acute geneeskunde & 4 & Th & 35 & Th \\
\hline & Beweging & 4 & Th & 12 & Th \\
\hline & Algemeen coschap & 5 & $\operatorname{Pr}$ & 3 & Nee \\
\hline
\end{tabular}

${ }^{*}$ Nog niet definitief gepland. 
en het zenuwstelsel behandeld werden. Het theoretische onderwijs in de spoedeisende geneeskunde was op de meeste faculteiten opgenomen in het gedeelte van het curriculum voorafgaand aan de klinische en/ of masterfase. In dit onderwijs kwamen stoornissen in A (airway = ademweg), B (breathing = ademhaling) en C (circulation = circulatie) uitgebreid aan bod, werden acute ziektebeelden behandeld en was er aandacht voor basale en specialistische behandelingsmogelijkheden. De fractuurleer kwam in alle curricula uitgebreid aan bod en was over het algemeen opgenomen in cursussen waarin het bewegingsapparaat behandeld werd. Er werd weinig onderwijs op het gebied van verslavingen en vergiftigingen gegeven. Ook wondbehandeling en verbandleer kwamen over het algemeen slechts zijdelings aan bod. Opvallend was dat op één medische faculteit de spoedeisende geneeskunde in het hele eerste jaar als uitgangspunt dient. De reden voor deze vroege introductie was het multidisciplinaire karakter van het deelgebied, waardoor het een goed onderwerp is voor de kennismaking met probleemgestructureerd onderwijs (tabel 1).

\section{Interviews}

\section{Algemene kenmerken van het onderwijs spoedeisende geneeskunde}

Uit de resultaten van de interviews met de curriculumcoördinatoren en docenten (en de inventarisatie op basis van de studiegidsen en cursusboeken) blijkt dat het praktische onderwijs in basale reanimatie minimaal twee keer in het curriculum werd aangeboden op alle acht faculteiten. Op sommige faculteiten werd het onderwijs volgens de docenten viermaal aangeboden. Dit werd echter door studenten niet altijd bevestigd. Opvallend was dat de studenten van deze faculteiten aangaven zelf EHBO-cursussen te organiseren.
Inhoud en doelstelling van het onderwijs Alle docenten die structureel onderwijs verzorgden in de diagnostiek en behandeling van stoornissen in vitale functies werden benaderd en namen deel aan het onderzoek. Het onderwijs werd gegeven door vakinhoudelijke experts. Slechts op een tweetal faculteiten werden eisen gesteld aan didactische kwaliteiten. Er werd aangegeven dat er een tekort aan docenten bestond. De inhoud en doelstelling van het onderwijs verschilden per medische faculteit. Kort zullen hieronder enkele kenmerken van de diverse medische faculteiten worden weergegeven.

Op faculteit $A$ was het onderwijs erop gericht een student op te leiden tot 'goed getrainde leek'. De student zou BLS moeten beheersen op het niveau van BLS met beperkte hulpmiddelen (bv. masker en ballon). Op het moment van het onderzoek was de ervaring dat coassistenten dit niveau bereiken. In de toekomst zou in het onderwijs meer gebruik gemaakt gaan worden van scenario-onderwijs.

Op faculteit $B$ werd ernaar gestreefd een student zodanig op te leiden dat hij in staat is leiding te geven aan een reanimatie en geïnteresseerd is in de achtergronden van de onderdelen van de BLS en ATLS. Aangezien onduidelijk was welk onderwijs de coassistenten ontvingen in de geaffilieerde ziekenhuizen, werden terugkomdagen voorgesteld, zodat een hernieuwde training kon worden aangeboden.

Op faculteit $C$ waren de deelnemers aan het onderzoek van mening dat in het curriculum voldoende aandacht besteed werd aan spoedeisende geneeskunde.

Op faculteit $D$ was het streven de student BLS goed te leren beheersen en kennis te laten nemen van de onderdelen van ALS. Tijdens de interviews werd echter aangegeven dat het onderwijs in de spoedeisende geneeskunde meer prioriteit zou moeten hebben in het curriculum. De 
docenten meenden dat het onderwijs herhaald zou moeten worden en dat een multidisciplinaire aanpak gewenst is.

Op faculteit $E$ was spoedeisende geneeskunde het thema van het hele eerste jaar. Het praktische onderwijs was ondergebracht in een skillslab, waar de studenten zich vrijwillig konden inschrijven voor cursussen. Het vaardigheidsonderwijs werd echter jaarlijks getoetst, hetgeen erin resulteerde dat de cursussen door 97\% van de studenten werd bezocht.

Op faculteit $F$ werden in het onderwijs voornamelijk de achtergronden van acute ziektebeelden en de behandeling van deze stoornissen in het ziekenhuis behandeld. Het praktische onderwijs was gericht op de opleiding van een student in de spoedeisende geneeskunde tot een niveau waarop hij kennis had genomen van de technieken en achtergronden van dit deelgebied. Hij moest in staat zijn om de vitale functies van een patiënt stabiel te krijgen en te houden.

Op faculteit $G$ was het theoretische onderwijs in de spoedeisende geneeskunde impliciet opgenomen in het curriculum. De docenten die in het onderzoek geïnterviewd werden, gaven aan dat meer onderwijs in de spoedeisende geneeskunde gegeven zou moeten worden.

Op faculteit $H$ was het streven de student na het volgen van het theoretische onderwijs geleerd te hebben om te denken in oplossingen van de acute problemen en het denken in diagnosen te verlaten. Op het gebied van vaardigheden was het doel van het onderwijs een student adequaat EHBO te laten verlenen. Vanwege het theoretische kader waarover de student kon beschikken en zijn morele verantwoordelijkheid als toekomstig arts moest een student geneeskunde in staat zijn een patiënt met een spoedeisende hulpvraag zodanig te behandelen dat deze stabiel kon blijven totdat gespecialiseerde hulpverleners zouden arriveren.
Indicatie doeltreffendheid van het onderwijs In de interviews met de jaarvertegenwoordigers werd meermalen door de studenten vermeld dat een student geneeskunde minimaal in staat zou moeten zijn om een slachtoffer op straat te reanimeren. Aangezien een student geneeskunde kiest voor een opleiding tot hulpverlener in de gezondheidszorg, zou hij een attitude moeten hebben waarbij hij de verantwoording neemt om in ieder geval vaardig te zijn binnen het deelgebied van de spoedeisende geneeskunde. Bovendien gaven de jaarvertegenwoordigers aan dat ook vanuit de maatschappij verwacht wordt dat een student geneeskunde minimaal adequaat EHBO kan verlenen. Veel jaarvertegenwoordigers waren van mening dat acute hulpverlening veel studenten aanspreekt en zich goed leent voor onderwijs. Herhaling van het onderwijs was volgens veel jaarvertegenwoordigers noodzakelijk om ook in een stressvolle praktijksituatie adequaat spoedeisende hulp te kunnen verlenen. Met uitzondering van de jaarvertegenwoordigers van één medische faculteit, gaven de jaarvertegenwoordigers aan dat het onderwijs te weinig herhaald werd. In tabel 2 zijn de VAS-scores van de jaarvertegenwoordigers opgenomen. Opvallend hierbij is het gegeven dat er geen toename van het zelfvertrouwen lijkt te zijn gedurende de studie, en dat het zelfvertrouwen betreffende spoedeisende hulpverlening bij kinderen veel lager is en blijft dan bij volwassenen.

\section{Discussie}

\section{Vereiste situatie}

De gehanteerde methoden in het onderzoek maakten een inventarisatie van het onderwijs mogelijk. In alle interviews werd aangegeven dat een arts de verplichting heeft om adequaat spoedeisende hulp te kunnen verlenen, zoals ook werd aan- 
Tabel 2 Gemiddelde VAS-scores jaarvertegenwoordigers, waarbij 0 geen en 100 een absoluut zelfvertrouwen aangeeft.

\begin{tabular}{|c|c|c|c|c|c|c|c|c|c|c|c|}
\hline & \multicolumn{2}{|c|}{ Luchtweg } & \multicolumn{2}{|c|}{ Ademhaling } & \multicolumn{2}{|c|}{ Circulatie } & \multicolumn{2}{|c|}{ Bewustzijn } & \multicolumn{3}{|c|}{ CPR } \\
\hline & Volw. & 0-8 jr.* & Volw. & 0-8 jr.* & Volw. & $0-8$ jr.* & Volw. & 0-8 jr.* & Volw. & $0-1$ jr.** & 1-8 jr.*** \\
\hline Jaar 1 & 36 & 31 & 44 & 35 & 65 & 55 & 68 & 63 & 49 & 29 & 35 \\
\hline Jaar 2 & 40 & 32 & 51 & 42 & 46 & 33 & 53 & 37 & 39 & 21 & 27 \\
\hline Jaar 3 & 65 & 41 & 66 & 52 & 56 & 45 & 74 & 59 & 58 & 30 & 46 \\
\hline Jaar 4 & 74 & 60 & 72 & 59 & 75 & 64 & 78 & 66 & 79 & 53 & 62 \\
\hline Jaar 5 & 43 & 35 & 49 & 37 & 49 & 42 & 56 & 45 & 46 & 31 & 37 \\
\hline Jaar 6 & 65 & 49 & 72 & 65 & 80 & 71 & 82 & 73 & 65 & 30 & 44 \\
\hline
\end{tabular}

gegeven in het Raamplan 1994 artsopleiding: “(...) de arts is in staat te kunnen handelen op minstens eerstehulpniveau, zoals thans omschreven in het Oranje Kruis-boekje" en in het Raamplan 2001 artsopleiding. ${ }^{1-3}$ Aangezien stoornissen in de vitale functies vaak in een stressvolle situatie gediagnosticeerd en behandeld moeten worden, is bovendien herhaling van het onderwijs noodzakelijk, zodat de handelingen een automatisme vormen. In het Raamplan 2001 artsopleiding wordt dit belang onderkend. In de algemene eindtermen wordt aangegeven dat een basisarts in staat moet zijn om basale eerste hulp te verlenen zoals beschreven in de ATLS. Deze ATLS-eisen zijn ontwikkeld voor hulpverleners met een BIG-registratie op het gebied van traumaopvang waarbij gebruik gemaakt wordt van geavanceerde technieken. Het verlenen van elementaire eerste hulp volgens de richtlijnen van het Oranje Kruis is echter een minimale vereiste voor alle (aankomende) artsen, zoals ook aangegeven door Severien en collegae. ${ }^{5}$

\section{Geconstateerde situatie}

De curricula zijn over het algemeen gericht op het opleiden van een student die basale reanimatie beheerst en uitgebreid kennis heeft genomen van de theoretische achtergronden. De docenten van de meeste medische faculteiten gaven aan dat het onderwijs in de spoedeisende geneeskunde als te beperkt wordt ervaren. Het onderwijs in de geavanceerde technieken en middelen is beperkt tot het geven van een demonstratie van de technieken die gebruikt worden bij het onderhouden van een vrije luchtweg met hulpmiddelen. Daarnaast komt de medicamenteuze behandeling van stoornissen in de vitale functies op alle acht faculteiten theoretisch aan bod. Slechts op vier faculteiten wordt onderwijs op het gebied van de spoedeisende geneeskunde aan kinderen aangeboden.

Uit dit onderzoek komt naar voren dat er soms te weinig tijd in het curriculum lijkt te zijn voor het onderdeel spoedeisende geneeskunde. Gedeeltelijk wordt dit opgevangen door het geven van EHBOcursussen door studenten(verenigingen).

Opvallend in de resultaten van dit onderzoek is het uitblijven van een toename van het zelfvertrouwen bij ouderejaars studenten en het lage vertrouwen in hun capaciteiten om spoedeisende hulp te verlenen aan kinderen. Alhoewel dit slechts een kleine groep studenten betreft (namelijk alleen de jaarvertegenwoordigers, maar hoogstwaarschijnlijk een positieve selectie), is dit resultaat verontrustend. Te meer daar er door studenten meestal een hogere mate van zelfvertrouwen in 
het verlenen van spoedeisende hulp wordt opgegeven dan gerechtvaardigd is. ${ }^{6-7}$ Dat het feitelijke niveau waarop zij de elementaire eerstehulpverlening en basale reanimatie beheersen inderdaad onvoldoende is, wordt ook gevonden in de studie van Severien et al. ${ }^{5}$ Het theorie-examen werd slechts door 10 van de 54 aankomende artsen (19\%) voldoende gemaakt. Een praktijkexamen werd slechts bij 6 studenten $(11 \%)$ als voldoende beoordeeld en bij het reanimatiescenario hadden slechts 16 personen $(30 \%)$ een voldoende. Volgens internationale criteria hadden hiervoor echter slechts drie studenten $(6 \%)$ een voldoende. Ook in studies uit landen als Nieuw Zeeland en Polen worden gelijkluidende resultaten vermeld. ${ }^{6-7}$

Diverse auteurs onderschrijven de verwachting die in de maatschappij bestaat dat een medewerker in de gezondheidszorg in staat is om elementaire eerste hulp te verlenen en basale reanimatie te verrichten. ${ }^{8-9}$ Deze en andere auteurs geven aan dat veel en herhaaldelijke oefening van groot belang is om zich deze vaardigheden eigen te maken en te onderhouden. ${ }^{5-11}$ Op basis van onze inventarisatie is het de vraag of aan deze voorwaarden voldaan werd in de Nederlandse medische faculteiten. Severien et al. ${ }^{5}$ adviseren op basis van de door hen geconstateerde feitelijke situatie: "Het belangrijkste lijkt ons het geven van een eerstehulp- en een basale reanimatiecursus, gebaseerd op het Oranje Kruis-boekje, bij voorkeur in het eerste jaar van het medisch curriculum, met minimaal jaarlijkse herhalingen en toetsingen."

\section{Conclusie}

De resultaten van dit onderzoek suggereren een onvoldoende inbedding van het onderwijs in de spoedeisende geneeskunde in de artsopleiding in Nederland. Op basis van deze inventarisatie pleiten wij, even- als Severien et al., 5 voor aanpassingen in het medisch onderwijs om een niveau te behalen waarop kennis en vaardigheden betreffende elementaire eerstehulpverlening en basale reanimatie voldoende zijn om deze ook daadwerkelijk in de praktijk te kunnen toepassen.

\section{Literatuur}

1. Metz JCM, Pels Rijcken-van Erp Taalman Kip EH, Brand Valkenburg BWM van den. Raamplan 1994 artsopleiding: eindtermen van de artsopleiding. Nijmegen: Universitair Publikatiebureau Katholieke Universiteit Nijmegen; 1994.

2. Metz JCM, Verbeek-Weel AMM, Huisjes HJ. Raamplan 2001 artsopleiding: bijgestelde eindtermen van de artsopleiding. Nijmegen: Universitair Publicatiebureau Katholieke Universiteit Nijmegen; 2001.

3. Het Oranje Kruis. Oranje Kruis boekje, officiële handleiding tot het verlenen van eerste hulp bij ongelukken. Leiden: Spruyt, Van Mantgem \& De Does; 1997.

4. Turner NMcB, Driesselhuis MP, Draaisma JMTh, Cate OThJ ten. Influence of the APLS and PALS courses on self-efficacy in paediatric resuscitation [poster]. Poster 8I 4. In: Programme and abstracts of the AMEE 2004 Conference; 5-8 september 2004; Edinburgh, UK. p. 4.111.

5. Severien I, Tan ECTH, Metz JCM, Biert J, Berden HJJM. Het niveau van eerstehulpverlening en basale reanimatie door aankomende artsen. Ned Tijdschr Geneeskd 2005;149:1756-7.

6. Grześkowiak M. The effect of teaching basic cardiopulmonary resuscitation - A comparison between first and sixth year medical students. Resuscitation 2006;68:391-7.

7. Price CSG, Bell SF, Janes SEJ, Ardagh M. Cardiopulmonary resuscitation training, knowledge and attitudes of newly-qualified doctors in New Zealand in 2003. Resuscitation 2006;68:295-9.

8. Perkins GD, Hulme J, Shore HR, Bion JF. Basic life support training for health care students. Resuscitation 1999;41:19-23.

9. Das M, Elzubier M. First aid and basic life support skills training early in the medical curriculum: curriculum issues, outcomes and confidence of students. Teach Learn Med 2001;4:240-6.

10. Starc B, Pecan M. Training of medical students in resuscitation at the University of Ljubjana. Resuscitation 1996;32:19-22.

11. Leah V, Whitbread M, Coats TJ. Resuscitation training for medical students. Resuscitation 1998;39(1-2):87-90. 


\section{De auteurs:}

Dr. J.M.Th. Draaisma, kinderarts, Universitair Medisch Centrum St. Radboud, Nijmegen.

Drs. G. Roest, wetenschappelijk medewerker, Universitair Medisch Centrum St. Radboud, Nijmegen.

Dr. R.G. van Kesteren, internist-intensivist, destijds werkzaam bij het Universitair Medisch Centrum Utrecht.

Prof. dr. A. Vulto, ziekenhuisapotheker en farmacoloog, Erasmus MC, Rotterdam.

\section{Correspondentieadres:}

Dr. J.M.Th. Draaisma, afdeling Kindergeneeskunde, Universitair Medisch Centrum St Radboud, Huispost 833, Postbus 9101, 6500 HB Nijmegen.

Belangenconflict: geen gemeld.

Financiële ondersteuning: geen gemeld.

\section{Summary}

Introduction: We studied in what way undergraduate medical curricula in the Netherlands deliver formal education in first aid and basic life support.

Methods: We studied documents and conducted semi-structured interviews with staff involved in this area of medical education.

Results: In 'Blueprint 2001: training of doctors in the Netherlands', the final objective is defined as: "the doctor is able to provide basic first aid and basic life support." The expected competency level for first aid and basic life support varies among the medical faculties between that of a well trained layman to that of a general practitioner. There appears to be a lack of both available time in the curriculum and teachers who have the appropriate medical and educational qualifications to teach these competencies. Students reported that their self-confidence with respect to first aid and basic life support did not increase over the course of the curriculum and that their confidence in respect of paediatric first aid and basic life support was and remained low.

Discussion and conclusion: The results suggest a difference between the desired and the actual situation. That is why we strongly advocate that medical curricula should be changed to ensure that students are offered a programme that ensures that they can achieve a sufficient level of knowledge and skills in first aid and basic life support to be able to apply these in practice. (Draaisma JMTh, Roest G, Kesteren RG van, Vulto A. First aid and basic life support in Dutch undergraduate medical education: an inventory. Dutch Journal of Medical Education 2006;25(3):117-124.) 